\title{
Wear and energy-saving freight bogie designs with rubber primary springs: principles and experiences
}

\author{
M Hecht \\ Institute of Sea and Land Transportation Systems, Department of Rail Vehicles, Technical University Berlin, Sekr. SG 14, \\ Salzufer 17-19, Berlin D-10587, Germany. email: Markus.Hecht@TU-Berlin.de
}

The manuscript was received on 8 April 2008 and was accepted after revision for publication on 22 July 2008.

DOI: 10.1243/09544097JRRT227

\begin{abstract}
The traditional radial steering bogie with swing hanger links is known to be trackfriendly but heavy, and expensive in investment and maintenance costs. Whereas the actual bogies with longitudinal stiff axle guidance such as Y25 cause severe wear on wheels and rails in curves, and also develop high running resistance in curves.

Bogies with rubbers springs like double rubber ring spring (DRRS), Leicht und LaermArm (LEILA) low weight and low noise, and Gigabox are a new feature with good behaviour in curves and on straight tracks. Good experience over many years with DRRS and $35 \mathrm{t}$ axle load on the German Rheinisch Westfaelische Elektrizitaetswerke (RWE) coal line prove its benefits. For the new designs, LEILA and Gigabox, which are being introduced into the market now, even higher benefits can be demonstrated. The principle design features and the benefits regarding lateral track forces, wear, and traction resistance are evident. Also noise behaviour is an increasing demand for freight operation.
\end{abstract}

Keywords: bogie, life cycle costs, wear, friction damping, hydraulic damping, radial steering, rail freight noise

\section{DEMANDS FOR BOGIES}

Besides the general demands like low cost and high reliability from the dynamic point of view, there are two main requirements:

(a) low dynamic forces;

(b) stable running.

Low dynamic forces are reached by good uncoupling, soft springs, and the avoidance of resonances by damping [1].

There is a general difference between friction damping and hydraulic damping. The latter is usually combined with rubber springs.

\section{DESIGN EXAMPLES}

The leaf-spring bogie (Fig.1) has several friction mechanisms [2]. At vertical deflections, there is relative movement between the several spring leaves. In addition, the swing hangers rotate around the pins, which give additional friction damping. In lateral and longitudinal directions, this kind of friction damping is the only damping mechanism. Usually, the movements in all three directions of motion are coupled. For instance, if a lateral track fault occurs, the wagon moves not only laterally but will tilt also. Therefore, vice versa movements in the leaf spring occur that also damp the lateral movement.

From the design principle, the friction damping forces are load depending, which is desired. Thus, there is also a very high sensitivity of the damping forces to design and production tolerances, which were neglected till now and may result in huge differences in behaviour among several vehicles of the same type, see reference [2].

At the three-piece bogie, a normal force $N$ is applied by the spring load on the wedge, which causes force $R$ on the friction surface (Fig. 2). Of course this effect occurs on the other side of the bolster also, which is not cut free in Fig. 2.

This friction mechanism works not only in the vertical direction, but also in the lateral direction, as long as the slack admits this kind of movement.

At the Y25 bogie, the friction damping (Fig. 3) is very similar to the three piece bogie. An inclined link, the so-called Lenoir link, causes a load relevant normal 


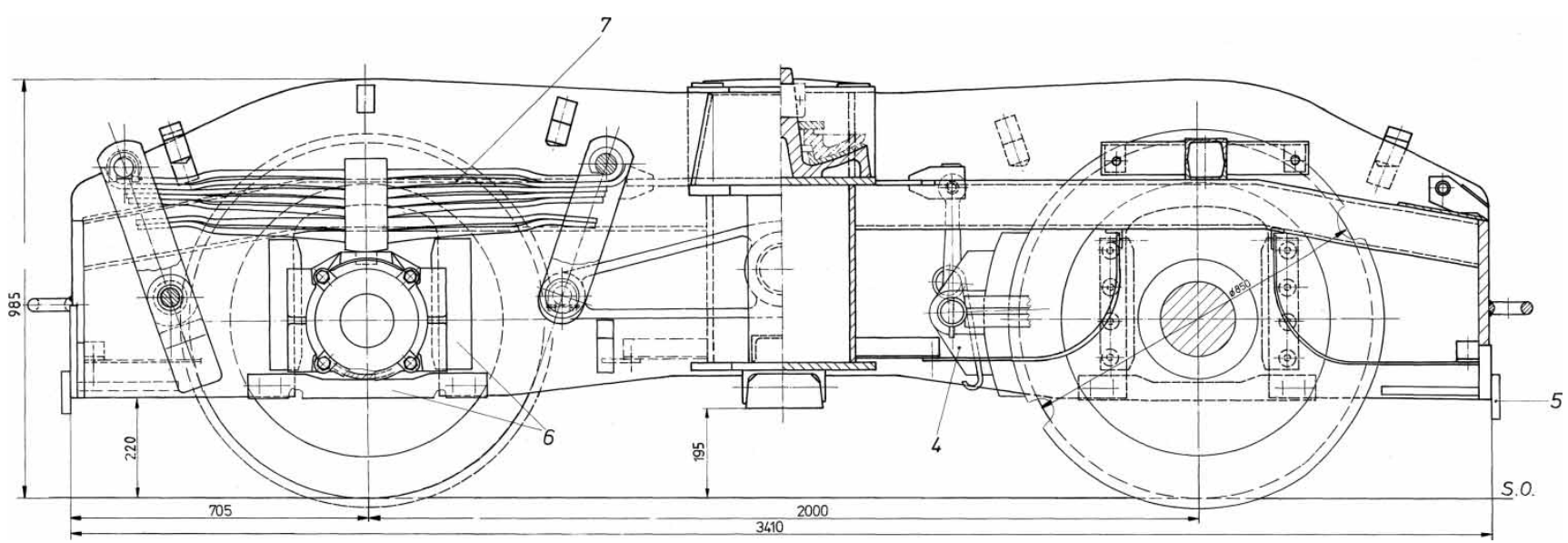

Fig. 1 Leaf-spring bogie with swing hangers of Rheinisch Westfaelische Elektrizitswerke (RWE) power for $35 \mathrm{t}$ axle load, maximum speed $65 \mathrm{~km} / \mathrm{h}$

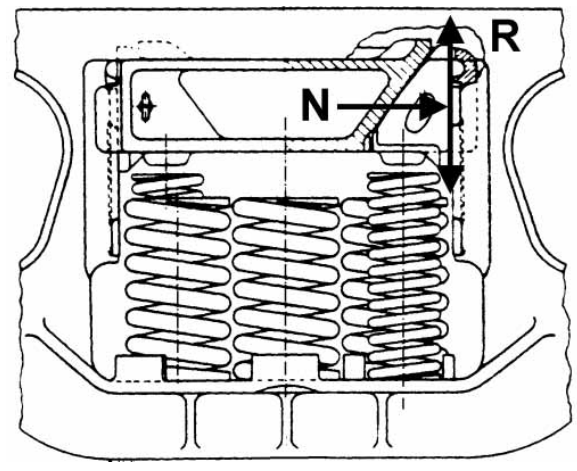

Fig. 2 Wedge damping device of the three-piece bogie

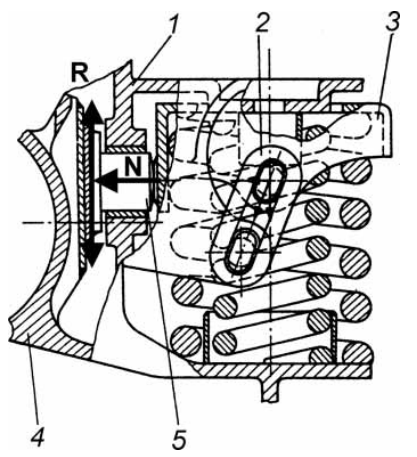

Fig. 3 Lenoir damping of the Y25 bogie: 1 bogie frame, 2 Lenoir link, 3 support, 4 axle box, and 5 piston

force $N$ between an axle box and a piston. Between the piston and the axle box, and also on the other side of the bearing between axle box and the bogie frame, a friction force occurs. This friction force not only works in the vertical direction but also in the lateral direction.

The displacement-force diagram of Y25 (Fig. 4) is much closer to the coulombs friction law than the diagram for leaf spring with swing hangers (Fig. 5). In the latter, some elasticity always softens the change of load directions.

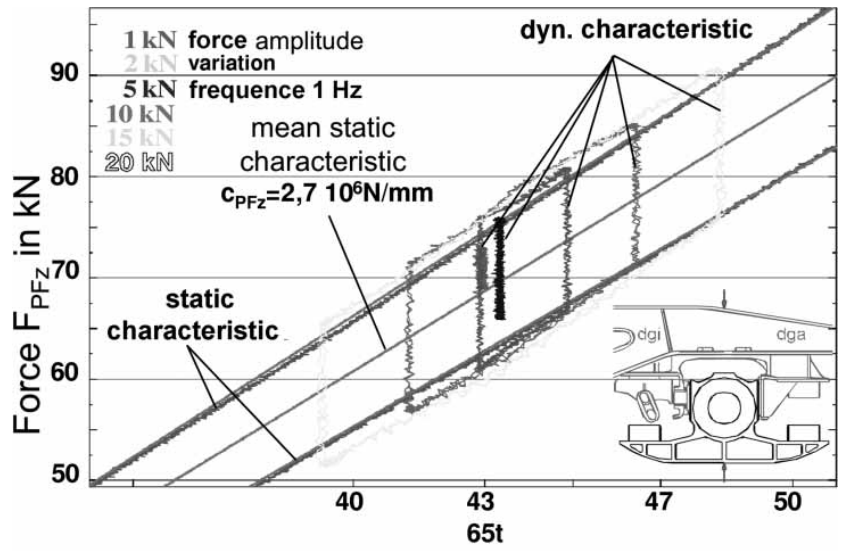

Displacement $\mathrm{s}_{\mathrm{PFz}}$ in $\mathrm{mm}$

Fig. 4 Displacement-force diagram of Y25 bogie suspension

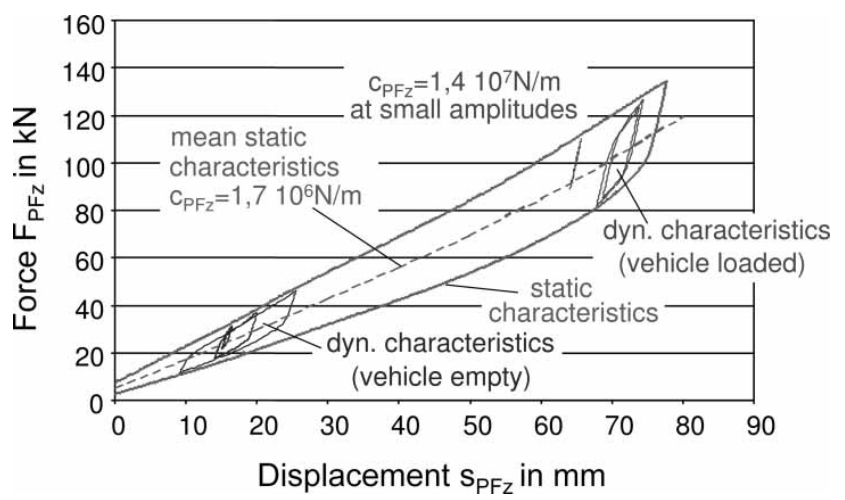

Fig. 5 Displacement-force diagram of a leaf spring primary suspension with swing hangers included for 20 t axle load

The main advantages of friction damping are low investment costs and that load sensitiveness can be implied easily. 


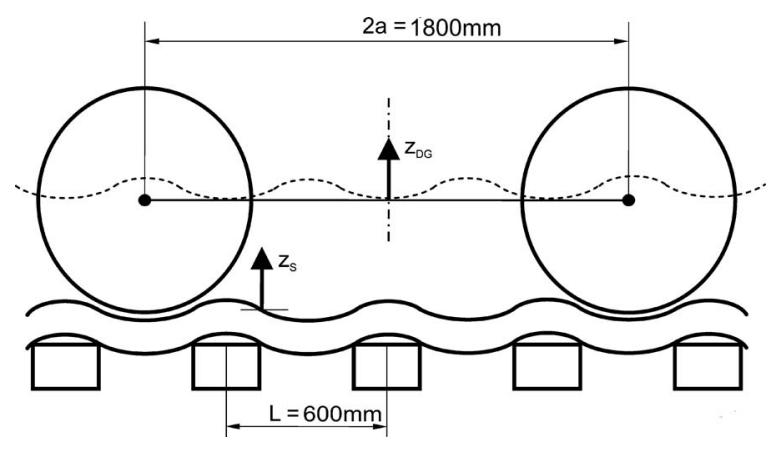

Fig. 6 Movement of both axle boxes and the bogie centre in phase

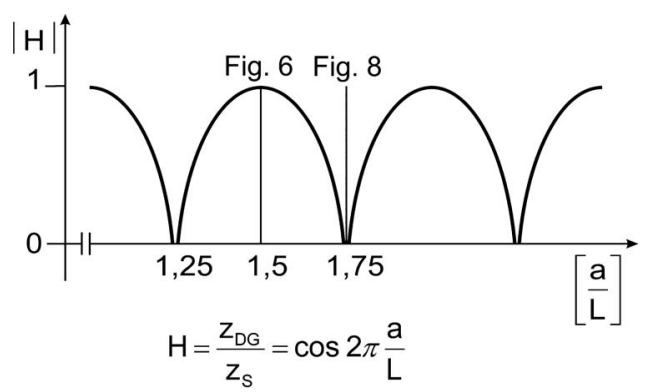

Fig. 7 Transfer function of the bogie between the movement of the rail displacement and the displacement of the pivot

There are several disadvantages.

1. With friction some kind of wear is always implied which inevitably involves maintenance costs.

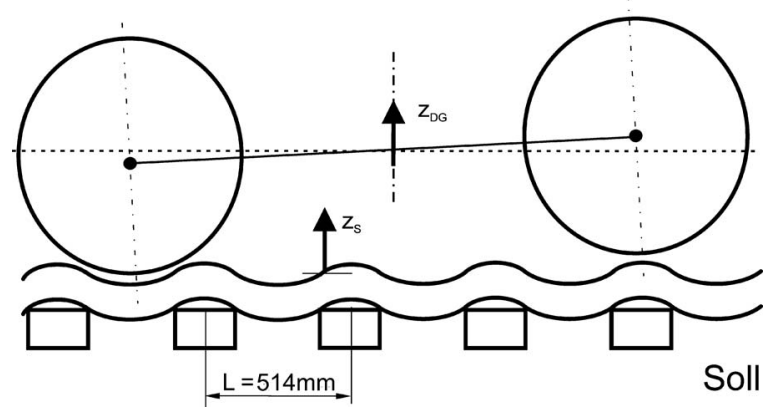

Fig. 8 Antiphase movement of the two wheel contact points and therefore zero movement of the pivot

2. As the friction surfaces are always open to the surrounding environment there are influences like dry or wet weather, and whether lubricants or some aggressive media like iron dust are present, which have a huge impact on them.

3. Also the behaviour from the principle has some problems (Figs 4 and 5).

The spring force and the friction force must be regarded together. For small forces and small displacements, the arrangement is very stiff. The nominal stiffness of the spring is reached at huge displacements only. This may occur, for instance, at a twisted rail in situations to avoid derailments.

In most situations, if there is a good track geometry accuracy then the spring system is blocked.

As the track-stiffness is higher if the wheel is on the sleeper, than when it is between sleepers these lead to parametric oscillations that are very significant in

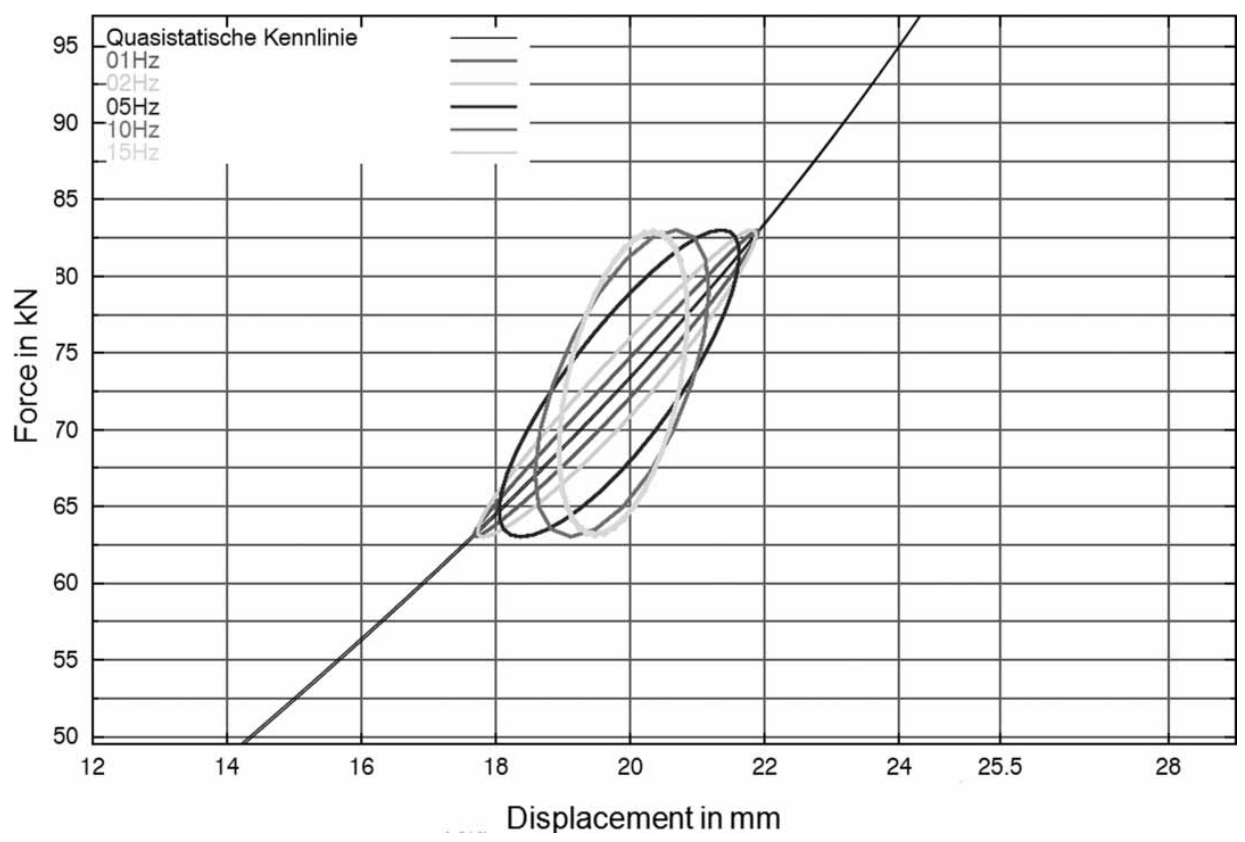

Fig. 9 Displacement-force diagram with a linear spring arrangement parallel to a hydraulic damping. Excitation with a force of $10 \mathrm{kN}$ at different frequencies from 1 to $15 \mathrm{~Hz}$ 


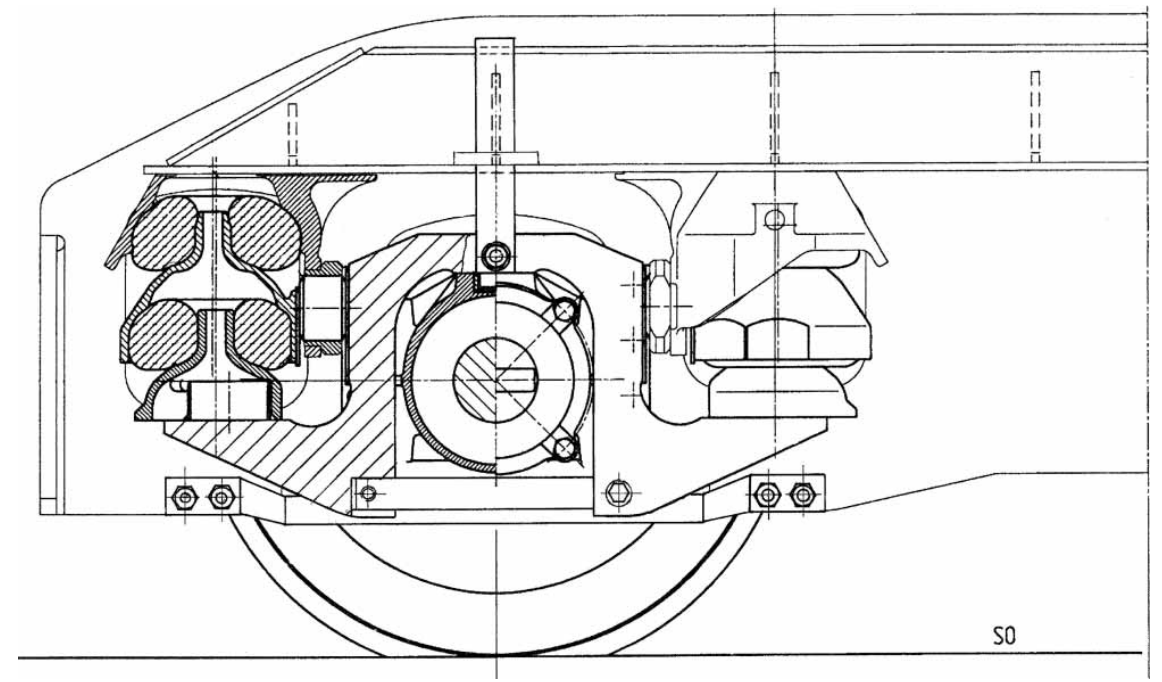

Fig. 10 Rubber-spring bogie DRRS of RWE power, axle load $35 \mathrm{t}$, maximum speed $65 \mathrm{~km} / \mathrm{h}$
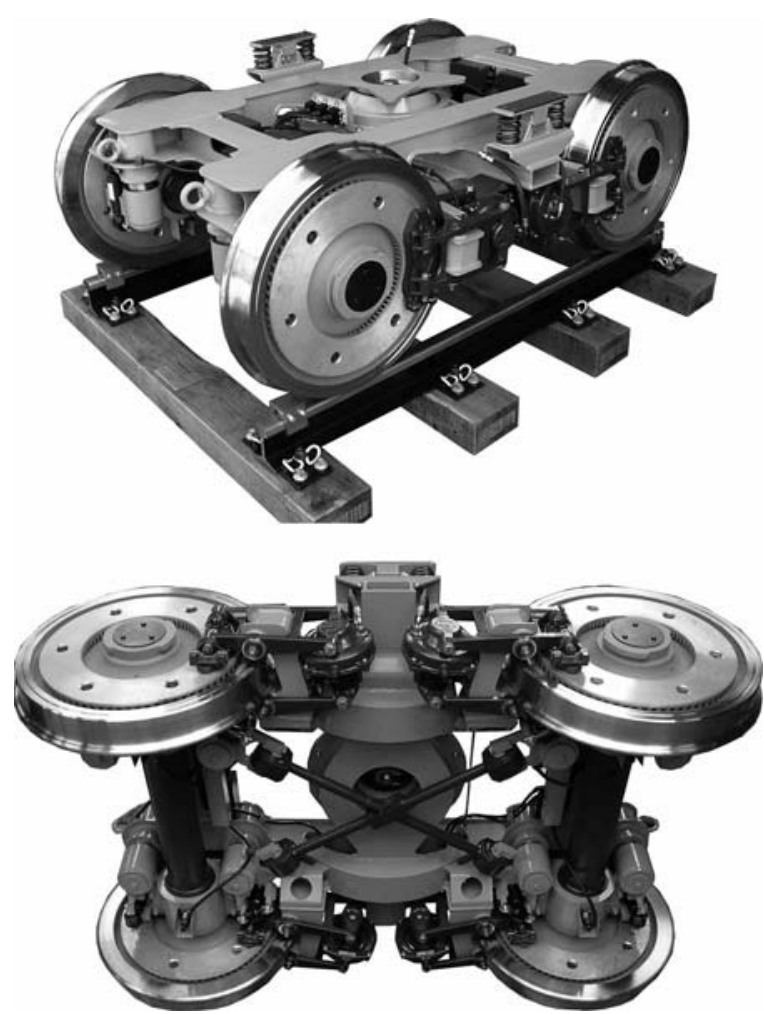

Fig. 11 LEILA bogie with linear hydraulic dampers, axle load $22.5 \mathrm{t}$, maximum speed loaded $120 \mathrm{~km} / \mathrm{h}$, above view from top, below view from bottom with cross anchors (JOSEF MEYER Transport Technology AG)

rail-freight as the axle distance of $1800 \mathrm{~mm}$ normally corresponds with three times the sleeper distance of $600 \mathrm{~mm}$. By this, the movements of the axle boxes are transferred to the bogie centre without reduction (Fig. 6) [3].

Figure 7 shows the transfer function $H$ of this phenomenon between the top of rail $z_{\mathrm{S}}$ and the bogie

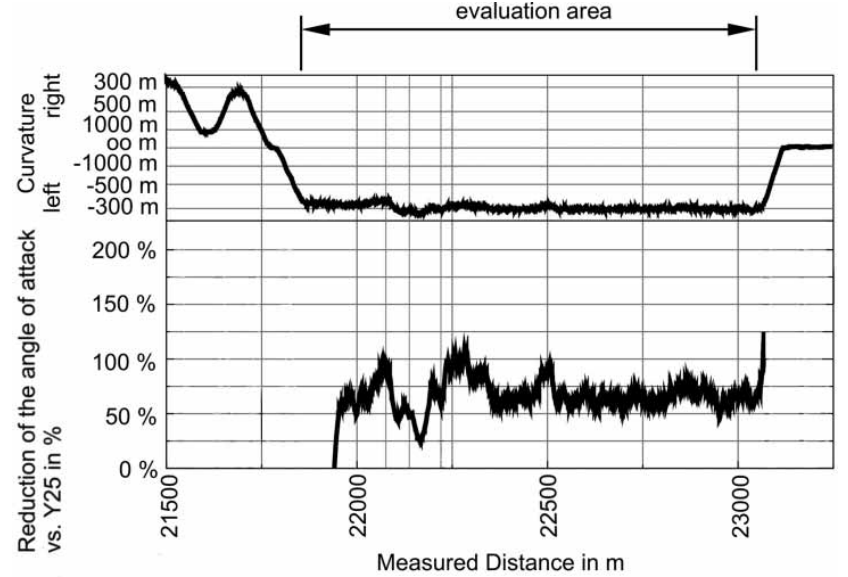

Fig. 12 Difference of the angle of attack LEILA versus Y25 bogie in a $300 \mathrm{~m}$ radius tunnel 'Leggistein', Gotthard Northramp Switzerland, constant speed $v=75 \mathrm{~km} / \mathrm{h}$, axle load $22.5 \mathrm{t}$ at both bogies

centre $z_{\mathrm{DG}}$ with a half axle distance, and $L$ is the wavelength.

This phenomenon could be avoided by shorter spacing of the sleepers (Fig. 8). Then one wheel of the bogie is at a hard area of the track while the other is in the soft, and vice versa. The Ofotbanan from Narvik, in direction Kiruna on the Norwegian side is installed according to these principles.

A much better damping mechanism instead of friction is hydraulic damping (Fig. 9).

The force amplitude is fixed at $\pm 10 \mathrm{kN}$. The higher the excitation frequency, the smaller the amplitude of movement, and the higher the dissipated energy per cycle. The dissipated energy is equivalent to the surface in the ellipses of the graph.

This behaviour is excellent as damping increases with higher speeds. 


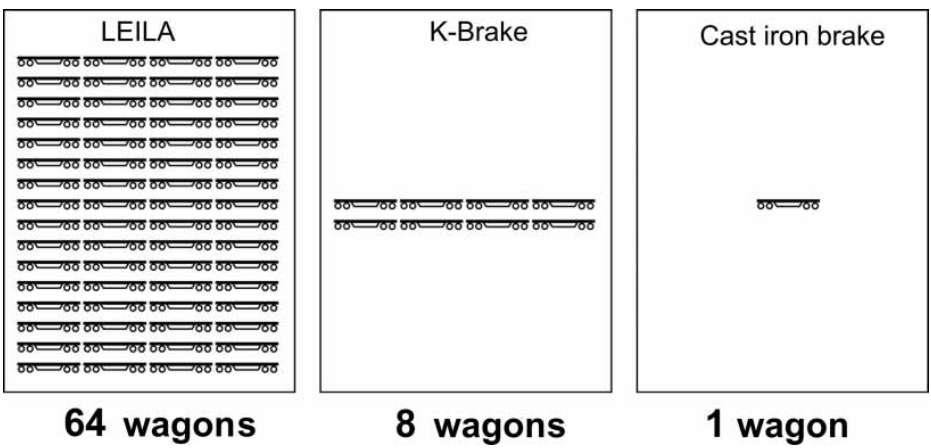

Fig. 13 Equal external noise for LEILA, $k$-braked Y25, and cast iron-braked Y25

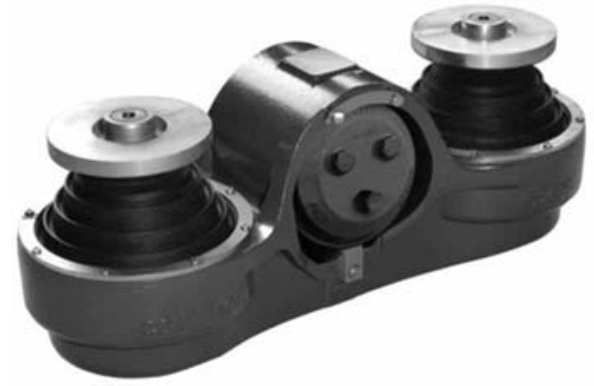

Fig. 14 Gigabox hydraulically damped rubber spring (ContiTech and SKF)

The older rubber spring design double rubber ring spring (DRRS) (Fig. 10) still uses friction damping similar to Fig. 4. Because of this, no significant longitudinal movement of the axle boxes and no significant wear reduction in the wheel-rail contact is possible along the curves. Nevertheless, the behaviour is better than with leaf-spring bogies.

Just the newer design of the Leicht und LaermArm (LEILA) low weight and low noise [4-6] bogie with inner bearings enables the use of a soft longitudinal rubber primary suspension (Fig. 11). It can be shown that with this design, energy savings of up to 25 per cent compared with the stiff bogie design, can be achieved [7]. Damping is achieved with two vertical hydraulic dampers per axle box (Fig. 11).

With the inner bearings, huge advantages are possible as more space becomes available for the application of rubber springs and dampers, and also designs are much simpler for the cross anchors.

There is a significant reduction of the angle of attack between wheel and rail. Figure 12 shows measured results of the difference of the angle of attack of a Y25 bogie and a LEILA bogie in a $300 \mathrm{~m}$ radius of a $180^{\circ}$ tunnel 'Leggistein' on the Gotthard Northramp in Switzerland. It is obvious that a reduction of more than 60 per cent is achieved. This means that the angle of attack is more than halved, which gives a huge benefit not only regarding the wear of wheel and rail but also in the traction force reduction or speed increase with the same traction force.
It is expected that the life of the bearing will be double the life of the wheel. Therefore, the bearing will stay on the axle if the wheel is replaced every second time.

As the load distribution between the pan and the wheels is more straightforward with inner than with outer bearings, there are significant weight reductions in the bogie frame and some weight reductions in the axle itself [4]. For $35 \mathrm{t}$ axle load, a weight reduction of $1 \mathrm{t}$ per bogie seems possible compared with the swing hanger type.

Also, energy consumption is reduced significantly on sinuous tracks [7].

For a fully loaded $90 \mathrm{t}$ wagon, simulations have shown nearly half of the running resistance compared with an Y25 bogie on lines such as KostheimOberlahnstein (right-hand line in the Rhine valley) or Gotthard south ramp [8]. As the other parameters are not affected, half the running resistance means nearly half the energy consumption.

Also, the noise behaviour could be, very much improved. Whereas a typical transit exposure level of a Y25 freight wagon with cast iron block brakes is $92 \mathrm{~dB}$ (A), the same bogie with composite brake blocks typically has $83 \mathrm{~dB}$ (A) whereas LEILA proves a level of $74 \mathrm{~dB}(\mathrm{~A})[6]$.

This means that 64 wagons with LEILA bogies pollute the environment the same way as eight wagons with Y25 bogies and composite brake shoes, or one Y25 wagon with cast iron brake shoes (Fig. 13).

The reasons for this are low noise wheels, wheel disk brakes, damping in the rubber primary suspension, but no additional noise dampers as described in reference [9].

The Gigabox uses the bogie frame from Y25, except for the primary suspension. At the primary spring design Gigabox (Fig. 14) there is a so-called hydrospring included: inside the rubber spring there are hydraulic viscous damping paddles that give specific damping forces in all three directions. With this design, very few elements are used in the suspension system. Even the slack adjustment is integrated into the element. The Gigabox is currently (2008) in test preparation with the German research project 'Leiser Zug Auf Realem Gleis' / quiet train on real track. 
Pre-tests led to expect rolling noise reductions of more than $2 \mathrm{~dB}$.

\section{CONCLUSION}

Friction damping, not hydraulic damping was used in bogies for one and a half centuries in rail-freight. It now seems obvious that there are many advantages regarding live cycle costs, traction energy savings, and noise reduction, so that hydraulic damping will replace friction damping during the next decades.

\section{REFERENCES}

1 Molatefi, H., Hecht, M., and Kadivar, M. H. Critical speed and limit cycles in the empty Y25-freight wagon. Proc. IMechE, Part F: J. Rail and Rapid Transit, 2006, 220(F4), 347-359.

2 Jönsson, P.-A., Andersson, E., and Stichel, S. Experimental and theoretical analysis of freight wagon link suspension. Proc. IMechE, Part F: J. Rail and Rapid Transit, 2006, 220(F4), 361-372.
3 Hecht, M., Jänsch, E., Lang, H. P., Lübke, D., Mayer, J., Mittmann, W., Pachl, J., Siegmann, J., and Weigand, W., Handbuch das system bahn, 2008 (Eurailpress, DVV Media Group, Hamburg).

4 Hecht, M. and Schirmer, A. The 'LEILA DG' project: a quiet, light-weight bogie for freight wagons. Railway Technical Review, 2004, pp. 33-38.

5 Hecht, M. New freight bogie is an important contribution for growth of rail-freight. Eur. Railw. Rev., 2002, 4, $61-64$.

6 Hecht, M. and Keudel, J. Advantages of the LEILA freight car bogie proved by test runs. ZEVrail Glasers Annalen 131, Tagungsband SFT Graz 2007, pp. 32-41.

7 Hecht, M. and Keudel, J. Verbesserte Energieeffizienz durch radialeinstellendes Fahrwerk. Eisenbahningenieur 5/2006, pp. 42-47.

8 Wichser, J., Schmidt, Ph., Bopp, B., Hecht, M., and Keudel, J. Potentiale durch den Einsatz von Radialeinstellenden Fahrwerken im Schienengüterverkehr im Hinblick auf die Energieeffizienz. ETH Zürich and TU Berlin, December 2007.

9 Thompson, D. J. and Gautier, P.-E. Review of research into wheel/rail rolling noise reduction. Proc. IMechE, Part F: J. Rail and Rapid Transit, 2006, 220(F4), 385-408. 